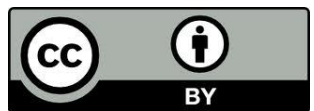

\title{
RELIGIÃO E "IDEOLOGIA DE GÊNERO” NO PLANO NACIONAL DE EDUCAÇÃO (PNE)
}

\author{
Religion and "Gender Ideology" in the National Plan of Educacion
}

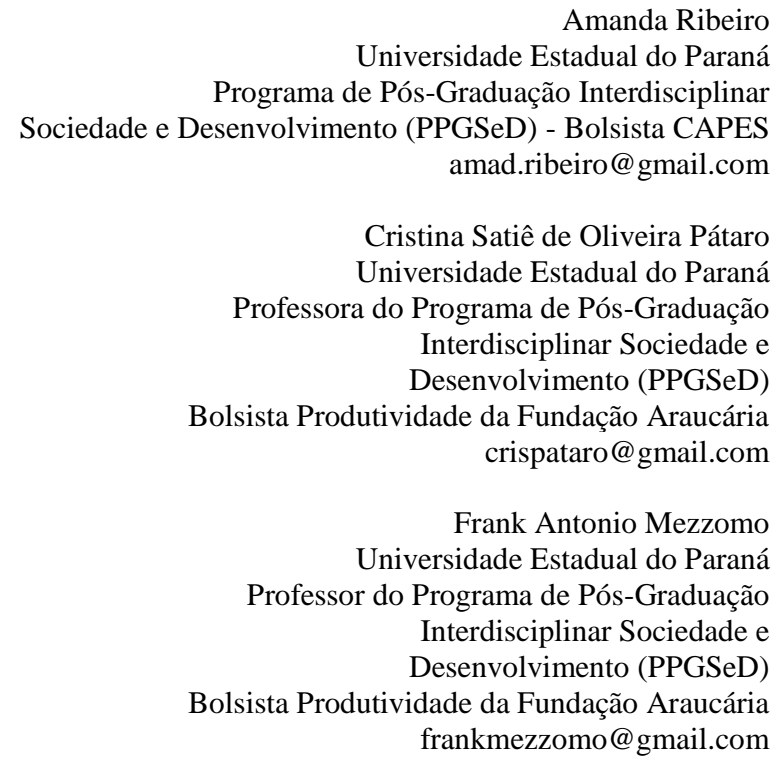

RESUMO: O artigo evidencia a influência de entidades e líderes religiosos na elaboração do Plano Municipal de Educação de Campo Mourão, município localizado no centro oeste do estado do Paraná. Busca-se evidenciar as disputas e formas de mobilização da população contra a "ameaça" exercida pelo que determinadas instituições religiosas passaram a denominar "Ideologia de gênero". A análise coloca em questão a presença da religião no espaço público, problematizando os movimentos e disputas políticas que têm sido protagonizados por agentes religiosos, inclusive na esfera da política institucional, em relação aos direitos reprodutivos e sexuais, assim como nas questões de gênero, trazendo repercussões também para o campo da educação.

Palavras chave: Religião; Política; Gênero; Educação.

ABSTRACT: This paper discuss the influence of religious entities and leaders in the drafting of the Campo Mourão Municipal Plan of Education, city located in the central west of the state of Paraná. It is aimed to highlight the disputes and paths to mobilize the population against the "threat" exercised by which certain religious institutions are calling "gender ideology". The analysis problematizes the presence of religion in public space, questioning the movements and political disputes that have been protagonized by religious actors, even in the institutional policy sphere, in relation to sexual and reproductive rights, and gender issues, bringing also implications for the field of education.

Keywords: Religion; Politics; Gender; Education. 


\section{Introdução}

O presente artigo analisa a presença da religião no espaço público, a partir de reflexões acerca da elaboração dos Planos Municipais de Educação, ocorridos no $2^{\circ}$ semestre de 2015, na esteira do que estabelece o Plano Nacional de Educação 20142024 (Lei n. 13.005/2014).

Para abordar esta temática, iniciamos com a problematização, ainda que breve, acerca da religião no espaço público, recorrendo aos conceitos de laicização e secularização, e apresentando de que forma a religião tem participado, no Brasil, das disputas políticas em relação aos direitos reprodutivos e sexuais, assim como nas questões de gênero. Em um segundo momento, a fim de ilustrar a presença da religião no espaço público, buscamos discutir a elaboração do Plano de Educação, com enfoque para o movimento ocorrido no município de Campo Mourão, no Paraná, visando demonstrar os posicionamentos das instituições e líderes religiosos diante da "ameaça" exercida pela chamada "Ideologia de gênero".

\section{Religião e espaço público: pluralidade, demandas e disputas}

No final do século XIX, o Brasil passa por um projeto de laicização, assim como ocorre com outros paíseslatino-americanos no mesmo período. Giumbelli afirma que “em se tratando de laicidade, nos deparamos com a aurora republicana como marco. É quando se adota de modo assumido o princípio da separação entre Estado e igrejas" (GIUMBELLI, 2008, p. 81). De acordo com o autor, nesse momento, há um rompimento com a Igreja Católica, o casamento passa a ser civil, o ensino é declaro como leigo, cemitérios passam a ser secularizados e princípios como o da liberdade religiosa são formalmente incorporados na primeira Constituição Republicana, a de 1891.

No Brasil, a Igreja Católica exerceu posição importante nas definições da nova relação entre a religião e o Estado, tendo se posicionado contra a separação entre Estado e religião, defendendo o reconhecimento da superioridade do catolicismo na formação da nacionalidade (GIUMBELLI, 2008).

Podemos dizer que o laicismo está associado ao pluralismo religioso, de modo que o termo laico não remete à ideia de "sem religião", mas à presença de várias denominações, à liberdade e imparcialidade religiosa, entendendo que as religiões não 
devem interferir ou influenciar os assuntos do Estado. Para Giumbelli (2008), a laicidade do Estado é princípio fundamental para a democracia, tendo em vista que as diferentes crenças podem ser exercidas sem que o Estado privilegie alguma delas, o que poderia gerar condições desiguais no acesso aos direitos.

Com relação ao movimento de secularização, e remetendo-nos ao período de constituição da modernidade ${ }^{1}$, Monteiro (2009) destaca que, numa acepção weberiana, o paradigma da secularização presume que o Estado, voltado para as questões do espaço público, se distanciaria de questões morais, enquanto que a religião passaria a se ocupar de questões relacionadas ao mundo privado, deixando de atuar em assuntos do poder político e concentrando suas ações nas consciências individuais. Ainda no entendimento de Monteiro, a ideia de secularização tem como base um pressuposto teleológico da história, compreendendo a modernização como um processo duplo que deve vir acompanhado do deslocamento da religião para a esfera privada, e no outro de proposições que orientam a forma como agir no mundo econômico e político. Assim, o conceito de secularização de Weber "supõe que as religiões de salvação, enquanto motor dos processos de modernização, se tornam, elas mesmas, cada vez mais racionalizadas e subjetivadas, deixando para trás a dimensão mágica que as caracterizou historicamente" (MONTEIRO, 2009, p. 08).

Afinado com essa noção weberiana, Pierucci (1997) entende que a liberdade religiosa, proporcionada pela separação entre Estado e Igreja, implicaria no pluralismo religioso, e esse, por sua vez, seria ao mesmo tempo resultado e um fator da crescente secularização. O autor entende que "a secularização consistiria, assim, em momentos em que os limites do campo religioso (muitas vezes arbitrários, posto que sempre cambiantes) alternadamente se contraem e se expandem” (PIERUCCI, 1997, p. 111).

Os movimentos de secularização e os desdobramentos da laicidade, sobretudo na experiência brasileira, acabam constituindo uma situação de não oposição e sim de complementação entre a religião e o Estado:

\footnotetext{
${ }^{1}$ Entende-se Modernidade como o momento que “'Deus todo-poderoso' passa a ser substituído pelo 'homem todo-poderoso': a crença no poder do homem é intensa, e isso se dá em função da crença no poder da razão, seja como guia das ações humanas. Inter-relacionada à crença no poder da razão está a ideia de progresso, uma vez que se concebe a própria razão como agente do progresso humano, o progresso ocorre na medida em que existe a aplicação crescente da razão no controle do ambiente físico e cultural" (ANDERY et al., 2007, p. 35).
} 
certas formas de presença da religião no espaço público não foram construídas por oposição à secularização, mas, por assim dizer, no seu interior. Em outras palavras, foi no interior da ordem jurídica encimada por um Estado comprometido com os princípios da laicidade que certas formas de presença da religião ocorreram (GIUMBELLI, 2008, p. 80-81).

$\mathrm{Na}$ esteira daquilo que afirma o autor, podemos constatar inúmeras influências exercidas pela religião/religiões na esfera política, sobretudo na constituição de "candidaturas religiosas", nas campanhas eleitorais e, por consequência, no lobby e pressão na construção de uma agenda política simpática aos interesses corporativos. A este respeito, diversos autores vêm apontando e problematizando acerca da presença cada vez mais intensa de agentes religiosos nos pleitos eleitorais, constituindo no Congresso Nacional e em alguns Estados as chamadas bancadas religiosas, composta majoritariamente por representantes de setores evangélicos (ORO, 2013; CAMPOS, 2015; MAIA, 2006; MIRANDA, 2006; MACHADO, 2006; MEZZOMO; PÁTARO; ONOFRE, 2014).

A presença cada fez maior dos agentes religiosos na política tem criado disputas que possibilitam às mais diferentes denominações religiosas defenderem suas pautas, sua presença e legitimidade no espaço público, favorecendo a pluralidade religiosa e os valores de liberdade e diversidade. Por outro lado, podemos dizer que o fortalecimento do discurso religioso tem agido, por vezes, no sentido de inibir a emancipação de grupos que, por suas características identitárias e demandas específicas, acabam contrariando os princípios de determinadas religiões. Como exemplo desse movimento, podemos mencionar as disputas políticas travadas em relação aos direitos reprodutivos e sexuais que vêm ocorrendo no Brasil, quando direitos têm sido negociados e debatidos por pessoas que, com frequência, utilizam-se de argumentos religiosos para tentar impedir sua aprovação em diferentes esferas da legislação brasileira e, ainda, anular direitos já conquistados (SOUZA, 2015; VITAL; LOPES, 2013).

A Frente Parlamentar Evangélica (FPE) tem sido um dos segmentos políticos que vem militado em favor da "defesa da família, dos bons costumes e da moral". Composta por deputados e senadores que se declaram evangélicos, logo em sintonia com uma identidade religiosa, têm se mantido e defendido uma pauta genericamente denominada de conservadora e de direita (SOUZA, 2015). A este respeito, vale ressaltar 
que a relevância e organização da atuação de evangélicos na política têm chamado a atenção e, em que pesem suas limitações, a diversidade do segmento e as competições internas entre denominações, não se pode ignorar que tal grupo religioso vem agindo "em prol da promoção de uma sociedade moralizada e civilizada a partir de seus termos", buscando constituir - se não no presente, talvez no futuro - um projeto político dos evangélicos para a sociedade (VITAL; LOPES, 2013, p. 179).

Nesse sentido, no entendimento de Souza (2015), a FPE tem atuado e se posicionado contra as leis em relação aos direitos sexuais e reprodutivos, assim como contra a chamada "Ideologia de gênero" nos Planos de Educação, discussão que ocorreu no país nos anos de 2014 e 2015. Para Souza:

No Congresso Nacional brasileiro, a relação de forças entre segmentos conservadores que têm se projetado nos últimos anos a partir de uma agenda moralista, apoiados por importantes grupos religiosos do Brasil e do exterior, e segmentos que lutam pelos direitos reprodutivos das mulheres e pelos direitos da população LGBT, indica complexas composições na arena político-religiosa do País no que tange ao debate sobre gênero e laicidade (SOUZA, 2014, p. 189).

$\mathrm{Na}$ política brasileira, o moralismo sexual é reivindicado por diferentes segmentos religiosos, como evangélicos e católicos, de modo que parte das pautas e das ações desses segmentos contemplam assuntos relacionados a sexualidade e moralismo. Cabe ressaltar que aagenda moralista/moralizante defendida por alguns políticos encontra eco não apenas nas lideranças religiosas, mas também junto a outros grupos e setores conservadores da sociedade (SOUZA, 2014). Essas ações político-religiosas podem ser consideradas uma violência de gênero, pois acabam por obstruir a luta pelos direitos da população LGBT e das mulheres, ao se movimentarem no sentido contrário aos direitos já conquistados por esses dois grupos.

Vários segmentos da Igreja Católica e de religiões evangélicas têm se pronunciado contra todas as moções e projetos de lei relacionados aos direitos da população LGBT e direitos reprodutivos das mulheres, utilizando-se das redes sociais e da atuação de políticos vinculados ao poder Executivo e Legislativo. A Igreja Católica

\footnotetext{
${ }^{2}$ A "Ideologia de gênero" afirmaria que o sexo biológico não define a sexualidade da pessoa, essa seria definida pelo meio social e cada individuo deveria ser livre para viver sua sexualidade. Essas ideias são entendidas como uma subversão da sexualidade humana e ameaçaria a família "natural" (SOUZA, 2014).
} 
ainda se vale do fato de que a maioria da população de nosso país se auto declara católica, para exercer sua influência. Souza destaca que:

Essa mesma pauta mobiliza alguns setores evangélicos, que também se utilizam fartamente das redes sociais, são representados pela bancada evangélica e, além disso, encontram em lideranças com ampla exposição na TV e no rádio uma forma muito eficaz, não apenas de transmissão, mas de produção de sua mensagem (SOUZA, 2014, p. 190).

Conforme exposto anteriormente, os movimentos delaicidade e secularização presumiriam a separação entre religião e Estado, e que as influências da religião nos assuntos do poder público seriam paulatinamente reduzidas, acabando por concentrar-se em questões relacionadas ao mundo privado. Contudo, podemos dizer que as discussões em relação ao tema dos direitos sexuais e reprodutivos mostram que a religião tem ocupando lugar de destaque na política, influenciando inclusive da definição de políticas públicas.

\section{A influência dos grupos religiosos nos Planos de Educação}

O Plano Nacional de Educação (PNE) define as metas, estratégias e diretrizes para a educação brasileira para os próximos dez anos (2014-2024), sendo base para a definição dos planos de educação de cada município, os quais devem articular suas metas às metas nacionais. O PNE, dado pela Lei n. 13.005/2014, está estruturado em quatro blocos: o primeiro contém as metas que preveem a garantia do direito à educação básica de qualidade ea promoção do acesso à educação; no segundo, constam as metas específicas sobre valorização da diversidade e redução das desigualdades, para que a equidade possa ser atingida; já no terceiro, destacam-se as metas em relação à valorização dos profissionais da educação; por fim, no quarto bloco contempla metas referentes ao ensino superior (BRASIL, 2014).

O PNE passou por uma longa trajetória até ser aprovado em 2014. Foi entregue em 2010 pelo Ministro da Educação Fernando Haddad ao então Presidente Lula, que o encaminhou para a Câmara dos Deputados que o aprovou em 2012. Na sequência, em 2014, foi submetido e aprovado pelo Senado, chegando à Presidenta da República, Dilma Roussef, que, em junho de 2014, o sancionou (ROSADO-NUNES, 2015). 
Devido às manifestações nacionais, por parte de segmentos da Igreja Católica e Evangélica, a palavra gênero foi retirada do PNE; o inciso III do artigo $2^{\circ}$ foi modificado para "superação das desigualdades educacionais, com ênfase na promoção da cidadania e na erradicação de todas as formas de discriminação" e a estratégia 3.12 da Meta 3 foi alterada para estratégia 3.13 da meta 3 “implementar políticas de prevenção à evasão motivada por preconceito ou quaisquer formas de discriminação, criando rede de proteção contra formas associadas de exclusão" (ROSADO-NUNES, 2015).

A partir da aprovação do Plano Nacional, cada município deveria elaborar e aprovar seu Plano de Educação até 24 de junho de 2015. A apresentação do PNE nos diferentes municípios brasileiros geraram inúmeras manifestações e polêmicas, sobretudo em torno da palavra gênero, presente no inciso III do artigo $2^{\circ}$, que previa a "superação das desigualdades educacionais, com ênfase na promoção da igualdade racial, regional, de gênero e de orientação sexual", além da estratégia 3.12, da Meta 3, que vinha assim definida: "implementar políticas de prevenção à evasão motivada por preconceito e discriminação racial, por orientação sexual ou identidade de gênero, criando rede de proteção contra formas associadas de exclusão".

As discussões se deram porque pessoas ligadas a igrejas, políticos e uma parte da população se posicionaram contra a utilização do termo gênero, sendo ainda contrários às iniciativas que previam tratar de temas relacionados à igualdade, orientação sexual, sexualidade e identidade de gênero no espaço escolar. Os grupos, contrário às diretrizes estabelecidas pelo Plano Nacional de Educação, afirmavamque tais expressões e a utilização do referido termo constituía a chamada "Ideologia de gênero", a partir da qual os conceitos de mulher e de homem estariam distorcidos, colocando em xeque o modelo tradicional de família e contrariando os princípios religiosos/cristãos. Por esses motivos, pediam a retirada da palavra gênero dos planos de educação (SOUZA, 2014).

Em face à repercussão do Plano Nacional, o Conselho Episcopal da Conferência Nacional dos Bispos do Brasil/Regional Sul II, correspondente ao Estado do Paraná, divulgou uma nota em 29 de maio de 2015, a qual solicitava que as lideranças da Igreja no Paraná se mobilizassem contra a adoção da "Ideologia de gênero". Destaca a nota que, após diversos protestos realizados pela Igreja, por ativistas pró-família e por parte 
da população, o Senado retirou itens referentes ao termo gênero/identidade de gênero presentes no texto do Plano Nacional de Educação. A nota alertava, ainda, que todos precisariam se mobilizar para que os mesmos termos fossem excluídos também dos Planos de Educação dos municípios, que deveriam ser aprovados em junho daquele ano: "Além dessa articulação capilar em todos os municípios paranaenses, é de se esperar que aconteçam reuniões em vários âmbitos com pessoas que atuam nas Secretarias de Educação e com Vereadores para um diálogo sobre a questão" (CNBB, Regional Sul II, 2015, p. 02).

No mesmo texto, a CNBB afirmava que a "Ideologia de gênero" excluía o conceito de sexo e corpo sexuado, sendo adotado em seu lugar a palavra gênero. De acordo com a fé cristã, a feminilidade e a masculinidade devem ser vistas como característica da pessoa, seu jeito de ser, não apenas um atributo, como estaria pressupondo a ideia de gênero. Essa "Ideologia", segundo a nota, defende que uma criança não nasce com um sexo definido e cada pessoa, quando cresce, deve decidir entre ser homem ou mulher. Dessa forma, afirma que:
A ideologia de gênero nega que a diferença sexual inscrita no corpo possa ser identificativa da pessoa; recusa a complementaridade natural entre os sexos; dissocia a sexualidade da procriação; sobrepõe a filiação intencional à biológica; pretende desconstruir a matriz heterossexual da sociedade (a família assente na união entre um homem e uma mulher deixa de ser o modelo de referência e passa a ser um entre vários) (CNBB, Regional Sul II, 2015, p. 02).

Os estudos de gênero têm como objetivo justamente a desnaturalização das condições das mulheres e a desconstrução do pensamento de que existem características próprias e inatas das mulheres e dos homens (MORENO, 1999; LOURO, 2012). As características atribuídas ao masculino ou feminino são construídas socialmente, variam de cultura para cultura, e são aprendidas socialmente onde os indivíduos assumem determinados comportamentos. Antes do nascimento, tais características já são introduzidas por meio de expectativas, que podem ser "traduzidas nas cores e brinquedos dos enxovais, na decoração dos quartos, na escolha dos acessórios e até na forma como a mãe se comunica com o bebê em seu ventre" (CARVALHO; TORTATO, 2009, p. 23), e que já trazem formas de entender o que seria ser homem ou mulher na 
sociedade onde está inserido.

De acordo com Souza (2014), quando assuntos relacionados a, por exemplo, direitos reprodutivos das mulheres e direitos da população LGBT surgem no Congresso Nacional brasileiro, há um confronto entre os segmentos conservadores, entre eles políticos religiosos, que lutam em defesa da família "natural", da moral e bons costumes, e grupos feministas e LGBT que lutam pelos direitos das mulheres e da população LGBT. Em muitos casos, esse confronto é vencido pelos grupos religiosos e leis e ações sobre esses temas deixam de ser aprovadas.

Em Campo Mourão, município localizado no centro oeste do estado de Paraná ${ }^{3}$, o Plano Municipal de Educação foi elaborado em 2015 pela Secretaria de Educação do município, inclusive com base em discussões realizadas em diferentes etapas pelo Fórum Municipal de Educação ${ }^{4}$. O referido plano foi enviado à Câmara dos Vereadores para aprovação, e, neste momento, setores eclesiásticos da Diocese de Campo Mourão se uniram aos pastores do município contra a chamada Meta 12 do Plano Municipal de Educação (PME), que previa a adoção de políticas públicas com o objetivo de estabelecer ações para fortalecer a prática educativa em relação à promoção da igualdade de gênero, de orientação sexual, étnico-racial e religiosa ${ }^{5}$. Esses agentes religiosos acreditavam que a aprovação dessa meta causaria no município prejuízos àmoral e àfamília, pois iriam contra os ensinamentos de Deus e o conceito de família natural.

O presidente da Ordem dos Pastores de Campo Mourão, pastor Arnildo Klumb, declarou, por meio de seu blog, ser contrário à meta 12 do PME, afirmando que a "Ideologia de gênero" iria contra os valores religiosos e da família. Para ele, essa Ideologia seria uma entrada para a pedofilia e o incesto, referidos pelo pastor como “identidades sexuais de gênero que hoje são crimes", mas que no futuro podem deixar de ser, pois os mesmos argumentos que sustentam a homossexualidade também as

\footnotetext{
${ }^{3}$ No município de Campo Mourão, 69,4\% da população se declara católica e 23,8\% evangélica. Em relação ao Paraná os números são semelhantes, já que $69,6 \%$ da população é católica e $22,2 \%$ se autodeclaram evangélicos. Tais números se aproximam da média brasileira em que 64,6\% são católicos e 22,2\% da população são evangélicos (IBGE, 2010).

${ }^{4}$ O Fórum Municipal de Educação de Campo Mourão foi instituído pelo Decreto Municipal n. 5994, de 7 de junho de 2013, contando com a participação de representantes e suplentes de diferentes órgãos, entidades e instituições do município.

5 Notícia veiculada na imprensa local, no Jornal Tribuna do Interior. Disponível em: http://www.itribuna.com.br/campo-mourao/2015/06/para-religiosos-projeto-enviado-por-regina-destroi-afamilia/1416759/. Acesso em: 22 set. 2016.
} 
legitimariam $^{6}$. Em sua manifestação, assim, o pastor compara a pedofilia e o incesto práticas criminosas - à homossexualidade, sugerindo que as discussões de gênero têm conduzido e incentivado a sociedade a práticas e relações contrárias aos valores religiosos.

Por parte da Igreja Católica, Dom Francisco Javier Delvalle Paredes, Bispo da Diocese, divulgou igualmente uma nota sobre o assunto, posicionando-se contrariamenteàmeta 12. Afirmou que os Bispos de todo o Brasil estavam se manifestando e, assim como ele, pedindo aos seus fiéis que olhassem com atenção a tentativa de doutrinação de gênero que estaria por se efetivar. Para o Bispo, aquele seria o momento da população se unir em nome da preservação dos valores humanos e cristãos, afirmando que essa "questão toca a responsabilidade de todo batizado e de todo cidadão, sem importar a qual religião, segmento ou associação pertença" (PAREDES, 2015). Na nota, ainda destacava que:

Os defensores desta ideologia querem plasmar a nova civilização futura anulando as diferenças inatas entre homem e mulher. Se não conseguem transgredir a opinião da geração presente, jáamadurecida em seus valores humanos e cristãos, intentam perspicazmente impor à sociedade o dever de educar as crianças, futuro da humanidade, segundo os ditames de tal ideologia (PAREDES, 2015).

No dia 15 de junho de 2015, ocorreu uma audiência pública na Câmara dos Vereadores do município de Campo Mourão para debater o PME. Nessa ocasião, a Câmara recebeu um grande número de pessoas que lotaram o local (Figura1), entre elas professores e alunos da Educação Básica e das Universidades, religiosos, pessoas vinculadas às igrejas de diferentes denominações. Vários portavam faixas e cartazes, contrários e favoráveis à manutenção do termo gênero disposto na Meta 12. Tal meta, conforme já previam os debates que antecipavam a sessão, foi o maior alvo das discussões realizadas.

\footnotetext{
${ }^{6}$ Blog do Pastor Arnildo Klumb, presidente da Ordem dos Pastores de Campo Mourão, PR. Disponível em: http://pastor-arnildo.blogspot.com.br/. Acesso em: 22 set. 2016.
} 
Figura 1: Sessão da Câmara Municipal de Campo Mourão no dia 15 de junho de 2015.

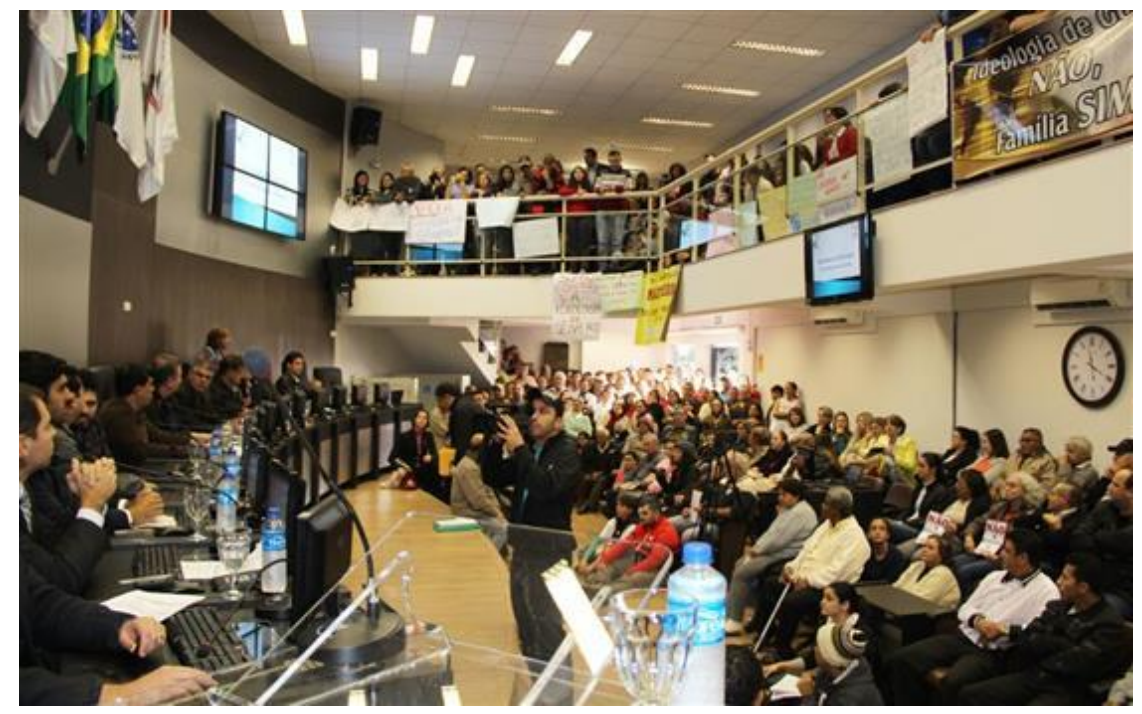

Fonte: Clodoaldo Bonete/Jornal Tribuna do Interior. Disponível em: http://www.itribuna.com.br/campomourao/2015/06/debate-sobre-pme-lota-camara-votacao-sera-quinta-e-sexta-feira/1417803/

Diversas pessoas se manifestaram ao longo da sessão, expondo seus argumentos em relação àposição que estavam defendendo, entre eles o Pastor Diego Dias do Amaral Bitencourt, o Padre Adilson Naruishi, o professor Anderson Rosa, o vereador Sidnei Jardim que se posicionaram contra a "Ideologia de gênero", e pessoas que argumentaram em favor da manutenção do termo gênero no referido plano, como professores universitários e outros membros da sociedade. Depois das discussões do dia 15, o presidente da câmara dos vereadores convocou duas sessões extraordinárias, que ocorreram nos dias 18 e 19 de junho para votar o plano.

O Plano Municipal de Educação do munícipio de Campo Mourão foi aprovado no dia 23 de junho de 2015. Após as manifestações e discussões, a Meta 12 foi alterada, suprimindo-se o termo gênero e prevendo, como segue, "Educação para a superação das desigualdades educacionais, com ênfase na promoção da cidadania e na erradicação de todas as formas de discriminação" (CAMPO MOURÃO, 2015, p. 107). Ainda, na estratégia 12.1, o texto aprovado afirma ser proibido "terminantemente o ensino da Ideologia de gênero e seus correlatos em todos os estabelecimentos de ensino do município" (CAMPO MOURÃO, 2015, p. 107). A despeito de tal observação, é possível verificar, ainda no documento, um item que versa sobre a educação para a igualdade racial, de gênero e de orientação sexual.

As discussões em torno da Meta 12 envolvendo os segmentos religiosos e 
ocorridas em Campo Mourão não se constituem como um caso isolado, tendo ocorrido em todo o Brasil, com intensidades e envolvimento de diferentes setores da sociedade. Em munícipios como Curitiba, Guarapuava e Maringá, no estado do Paraná, São Paulo e Campinas, no estado de São Paulo, entre outros, também foram noticiadas as manifestações a respeito do tema, também liderados pelos segmentos religiosos ${ }^{7}$.

No caso relatado, é válido destacar a atuação conjunta da Igreja Católica e das Igrejas Evangélicas para a mobilização da população contra a Meta 12 do Plano Municipal de Educação do município. O movimento evidencia a força e a presença da religião no espaço público, pautando e defendendo suas demandas. Ademais, a atuação dos agentes religiosos na política - eleitos para os cargos no legislativo - acabam por potencializar a força das religiões nos debates e disputas travadas entre as pautas das Igrejas e de outros grupos sociais - minoritários ou não.

Como se pode verificar, ainda que a laicidade tenha separado o Estado e a Igreja (GIUMBELLI, 2008), a influência da religião permanece - mesmo que, agora, exercida por diferentes denominações e não apenas pela Igreja Católica. Ademais, como pudemos verificar, a secularização (MONTEIRO, 2008; PIERUCCI, 1997) não significou nem o fim da religião e nem seu confinamento à esfera privada: a religião agora plural - permanece forte, presente e atuante, inclusive na esfera da política.

\section{Considerações finais}

Podemos notar no Brasil contemporâneo, que a religião tem ocupado grande espaço na política nacional, em diversas e diferentes esferas da sociedade e temas sociais. Como já vem sendo evidenciado por grande parte da literatura das Ciências Sociais, é grande a presença de pessoas ligadas a alguma igreja nas Câmaras de Vereadores, Câmara dos Deputados, Senado, e mesmo nos cargos ao Executivo. Por meio desses agentes, os valores religiosos vêm influenciando a criação de leis, em especial, no caso do presente texto, quando os assuntos vão contra os valores e crenças

\footnotetext{
${ }^{7}$ Para conferir algumas discussões realizadas em Curitiba, Guarapuava, Maringá, São Paulo e Campinas, acessar: ttp://ipco.org.br/ipco/em-curitiba-votacao-sobre-ideologia-de-genero-no-pme/\#.V3BMMrgrK00; http://www.guarapuavaeregiao.com.br/ultimas-noticias/noticias-de-guarapuava/ideologia-de-genero-foisuprimida-do-plano-municipal-de-educacao-de-guarapuava.html; $\mathrm{http} / / \mathrm{g} 1 . \mathrm{globo} . \mathrm{com} / \mathrm{pr} / \mathrm{norte}$ noroeste/noticia/2015/06/plano-de-educacao-e-aprovado-com-polemica-sobre-generos-em-maringa.html; http://g1.globo.com/sao-paulo/noticia/2015/08/camara-de-sp-aprova-em-1-votacao-plano-municipal-deeducacao.html; http://g1.globo.com/sp/campinas-regiao/noticia/2015/06/sob-tensao-camara-de-campinasrejeita-chamada-ideologia-de-genero.html.
} 
religiosas, como na situação das pautas da população LGBT, dos direitos reprodutivos das mulheres, do aborto, entre outros. Os argumentos utilizados para barrar tais leis são, geralmente, de ordem religiosa, acionados por um discurso em defesa "da família, da moral e dos bons costumes".

Com base em nossa análise do Plano Nacional de Educação e do Plano Municipal de Educação do munícipio de Campo Mourão, podemos constatar que as diferentes entidades religiosas influenciaram os textos desses planos. Essas entidades mobilizaram a população contra o que chamam de "Ideologia de gênero", pois os valores defendidos pelos estudos de gênero vão contra os valores defendidos pelas igrejas. Dessa forma, podemos dizer que a presença da religião no espaço público expressa as disputas travadas entre as demandas e princípios defendidos pelos grupos religiosos, de um lado, e, de outro, por distintos grupos sociais (religiosos ou não).

\section{.Referenciais}

ANDERY, Maria Amalia et al. Para compreender a ciência: uma perspectiva histórica. Rio de Janeiro: Garamond, 2007.

BRASIL. Ministério da Educação / Secretaria de Articulação com os Sistemas de Ensino (MEC/ SASE). Planejando a Próxima Década Conhecendo as 20 Metas do Plano Nacional de Educação. 2014. Disponível em: $<$ http://pne.mec.gov.br/images/pdf/pneconhecendo20metas.pdf $>$. Acesso em: 22 set. 2016.

CAMPO MOURÃO. Lei n. 3.604, de 23 de junho de 2015. Plano de Educação do Município de Campo Mourão. Órgão oficial do Munícipio. Campo Mourão. 23 de junho de 2015.

CAMPOS, Roberta Bivar Carneiro et al. A disputa pela laicidade: uma análise das interações discursivas entre Jean Wyllys e Silas Malafaia. Religião e Sociedade, Rio de Janeiro, v. 35, n. 2, p. 165-188, 2015.

CONFERENCIA NACIONAL DOS BISPOS DO BRASIL. Mobilização das lideranças da Igreja no Paraná contra a adoção da Ideologia de gênero. 2015. Disponível em: $<$ http://www.diocesedefoz.org.br/home/wp-content/uploads/Ideologiade-g\%C3\%AAnero-CNBB.pdf >. Acesso em: 22 set. 2016.

GIUMBELLI, Emerson. A presença do religioso no espaço público: modalidades no Brasil. Religião e Sociedade, Rio de Janeiro, v. 28, n. 02, p. 80-101, 2008.

LOURO, Guacira Lopes. Gênero, sexualidade e educação: uma perspectiva pósestruturalista. Petrópolis: Vozes, 2012. 
MACHADO, Maria das Dores Campos. Política e religião: a participação dos evangélicos nas eleições. Rio de Janeiro: FGV, 2006.

MAIA, Eduardo Lopes Cabral. Os evangélicos e a política. Revista Em Tese, Florianópolis, v. 2, n. 2, p. 91-112, ago./dez. 2006.

MEZZOMO, Frank Antonio; PÁTARO, Cristina Satiê de Oliveira; ONOFRE, Lucas. Evangélicos na política: as eleições proporcionais de Campo Mourão em 2012. Rever, São Paulo, v. 14, p. 244-264, 2015.

MIRANDA, Júlia. O candidato da igreja: do que nos fala a sua presença na política brasileira. In: LEMENHE, Maria Auxiliadora; CARVALHO, Rejane Vasconcelos Accioly (Orgs.). Política, cultura e processos eleitorais. Fortaleza: Fundação Konrad Adenauer, 2006.

MONTEIRO, Paula. Secularização e espaço público: a reinvenção do pluralismo religioso no Brasil. Etnográfica, v. 13, n.01, p. 07-16, maio 2009.

MORENO, Montserrat. Como se ensina a ser menina. São Paulo: Moderna, 1999.

ORO, Ari Pedro. Religião e eleições 2012 em Porto Alegre. Debates do NER, Porto Alegre, ano 14, n. 23, p. 109-144, 2013.

PAREDES, Dom Francisco Javier Delvalle. Nota pastoral sobre o Plano Municipal de Educação (2015-2024) e a ideologia de gênero. Campo Mourão, 08 de junho de 2015. Disponível em: <https://goo.gl/bp8Tuh>. Acesso em: 22 set. 2016.

PIERUCCI, Antonio Flávio. A propósito do auto-engano em sociologia da religião. Novos Estudos CEBRAP, São Paulo, n. 49, p. 99-117, nov. 1997.

ROSADO-NUNES, Maria José Fontelas. A "ideologia de gênero" na discussão do PNE: a intervenção da hierarquia católica. Horizonte, Belo Horizonte, v. 13, n. 39, p. 1237-1260, jul./set. 2015.

SOUZA, Sandra Duarte de. "Não à ideologia de gênero!" A produção religiosa da violência de gênero na política brasileira. Estudos de Religião, v. 28, n. 02, p. 188-204, jul./dez. 2014.

SOUZA, Sandra Duarte de. Mulheres evangélicas na política: tensionamentos entre o público e o privado. Horizonte, Belo Horizonte, v. 13, n. 39, p. 1261-1295, jul./set. 2015.

VITAL, Christina; LOPES, Paulo Victor Leite. Religião e política: uma análise da atuação de parlamentares evangélicos sobre direitos das mulheres e de LGBTs no Brasil. Rio de Janeiro: Fundação Heinrich Böll, 2013. 
Recebido: 08/10/2016

Received: 10/08/2016

Aprovado: $01 / 11 / 2016$

Approved: 11/01/2016 